\title{
A PRELIMINARY INVESTIGATION INTO THE RELATIONSHIP BETWEEN PLANT HEALTH AND BRANCH LABELLING TECHNIQUE AT THE ROYAL BOTANIC GARDEN EDINBURGH
}

\author{
Paul Bradley ${ }^{1} \&$ Robert Cubey ${ }^{2}$
}

\begin{abstract}
Anecdotal evidence exists at the Royal Botanic Garden Edinburgh (RBGE) to suggest that branches bearing plant labels are more prone to die-back than those without labels. During 2010-2011 a preliminary study was undertaken in order to assess the accuracy of this hypothesis and to investigate the possible causes and viable alternatives. The study focused on whether there were patterns of damage with respect to label material and wire, plant species or the location of plantings. The study involved a survey of the Living Collection in the four RBGE Gardens, a web-based questionnaire sent out to Botanic Gardens Conservation International member gardens and analysis of branch material and labelling wire. This report provides the information obtained when the hypothesis was investigated and makes recommendations. An extended version, along with the data gathered, is available in the Library at RBGE (Bradley, 2011).
\end{abstract}

\section{INTRODUCTION}

Plant labels are vital to the integrity of botanic garden living collections. They link growing plants to data in corresponding records and identify them to visitors, students and staff. There are many different labelling methods but, generally speaking, the ideal label is attractive and cost effective, and the information on it is clearly visible (Maurer, 1999). The growth of trees and shrubs means that they require a label that is directly attached and durable.

In this paper five types of labels are referred to:

- 'Display labels' are engraved plastic labels used for plants on display.

- 'Hanging labels' are display labels attached to the plant by a loop of wire and hung from a branch.

- 'Tally tags' are embossed metal tape labels for curatorial and staff use which often provide a back-up to display labels and contain only the accession information for the plant.

- 'Nursery tags' are temporary plastic tags containing accession information which are attached to plants in the Nursery. When plants are moved from the Nursery and planted out for display they will have a nursery tag.

- 'Trunk tags' are display labels screwed to a tree using a brass screw.

1. Paul Bradley was an HND student in Horticulture with Plantsmanship at the Royal Botanic Garden Edinburgh and finished his studies in June 2011. Address: 9 Cleuch Road, North Middleton, EH23 4RB. Email: P.Bradley@googlemail.com 2. Robert Cubey is Plant Records Officer at the Royal Botanic Garden Edinburgh. 
Many botanic gardens publish their own guidelines in order to achieve consistency and quality in plant labelling. At RBGE, labelling is carried out in accordance with the RBGE Horticultural Division Method Statement 3.5 (Horticulture Division, 2004). Plants on display normally have a temporary printed nursery tag attached by copper wire. A trunk tag is usually attached to trees and these are often accompanied by a second label hung at eye level on one of the lower canopy branches. On shrubs, there is normally only one tag, which is attached to one of the more conspicuous branches. More recently, in some of the displays a tally tag using either thin galvanised wire or plastic ties has been added. These show only the accession number and qualifier and act as a back-up to the standard black display label. Currently, the method of attachment for the display label is loosely tied enamelled copper wire.

It has been observed by staff at Benmore Botanic Garden that when copper wire is used to attach aluminium tally tags, the aluminium becomes corroded (Baxter, pers. comm.). This indicates the effects that copper leach can have and has prompted further investigation into copper leach onto plant material.

Anecdotal evidence exists to suggest that labels attached to branches are harmful to plants. If this can be proven then the implications for the Living Collection are significant. The present authors are not aware of any formal studies that have been conducted on this issue; however, it was raised by Robert Cubey at a meeting of Senior Horticulturists at RBGE in 2010 and consequently the Curators of the four RBGE Gardens agreed to monitor the situation on an informal basis.

\section{DAMAGE TO BRANCHES CAUSED BY LABELLING}

Informal enquiries made by the authors prior to this study established that there are a number of opinions held by staff on why attaching a label to a branch might kill it. One suggestion is that constriction can occur at the point where the wire is attached if the girth of the branch outgrows the size of the wire loop. This can reduce or stop the flow of water and sap and the resultant wound could become a weak point that would increase the plant's susceptibility to pathogens (Goren et al., 2010). This type of branch girdling is a known phenomenon and examples can be found in many living collections.

Accidental girdling is easy to diagnose and was not the focus of this investigation. The concern raised was that branch death seemed to occur where loosely attached labels were located (see Fig. 1). One opinion relating to this type of damage was that the force of the wind on a loosely attached label agitates the wire, which eventually cuts through the outer layer of thin-barked species. This effectively girdles the branch without constricting it.

Two other opinions were offered on the detrimental effects of wire label ties: the first was that the wire heats up in summer or cools down in winter to such extremes that it affects the bark. The second was that phytotoxic levels of copper leach from the wire during periods of rain or snowfall. Although copper is an essential element for plant 


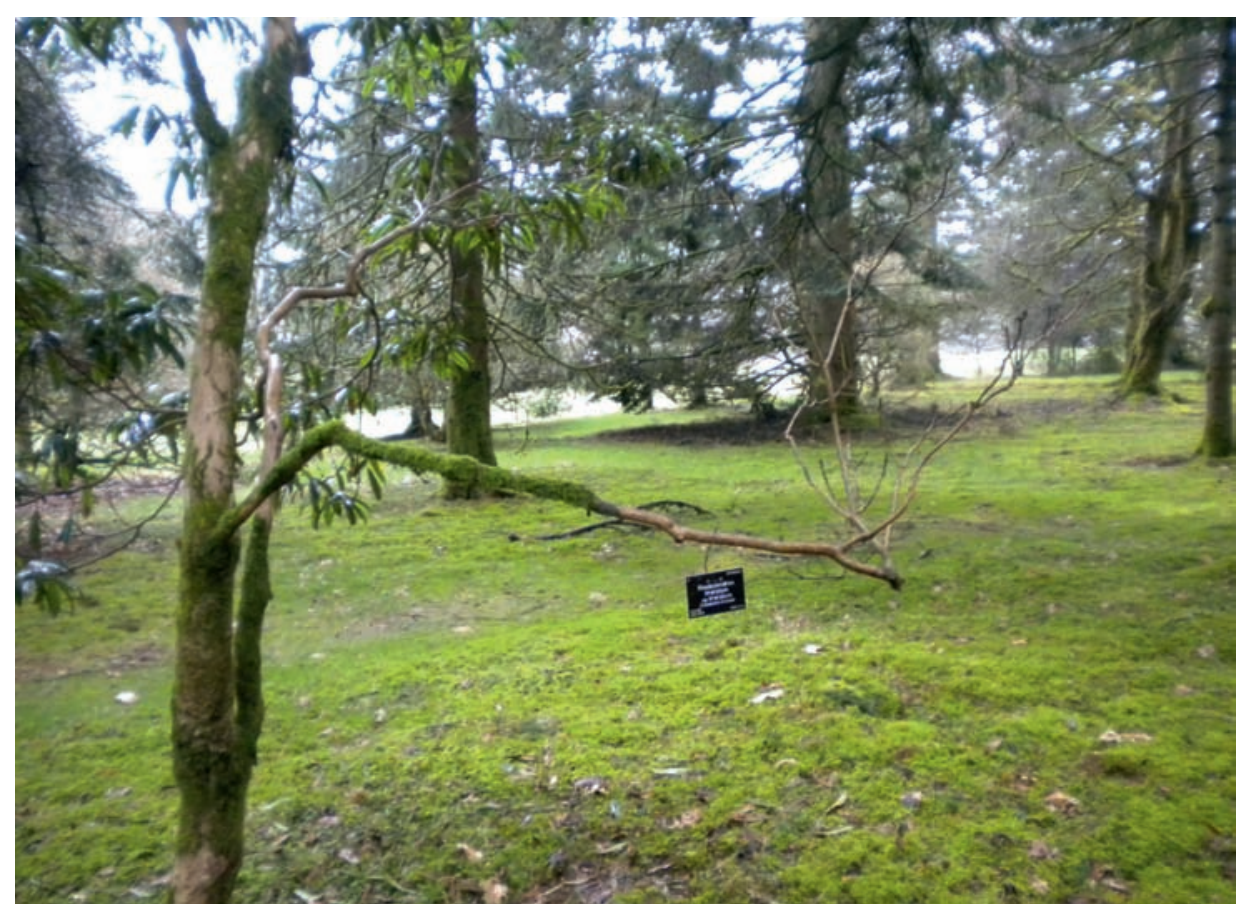

Fig. 1 A healthy specimen of Rhododendron irroratum at Benmore Botanic Garden with one dead branch on which the label is attached. Photo: Paul Bradley.

growth, it has been proven to cause chronic poor health in woody ornamental species at solution levels above only 1ppm (Kuhns \& Sydnor, 1976).

Some horticulturists were of the opinion that it is simply coincidence that some branches to which labels are attached have died, whilst others suggest that the lower branches, which are convenient for hanging labels, are lost naturally through senescence or by being in the shade of the higher branches.

\section{AN ASSESSMENT OF WIRE USED TO ATTACH LABELS AT RBGE}

The wire currently in use at RBGE is a shaped enamelled wire called Magnetemp ${ }^{\circledR}$ CA 200. It is coated with THEIC-modified polyesterimide and polyamide imide and is normally used in the windings of electrical motors. The specifications of this product indicate that it has been designed to have excellent chemical and abrasion resistance and is durable up to exceptionally high temperatures (over $200^{\circ} \mathrm{C}$ ). In good conditions this wire is extremely resistant to leaching copper. The polyamide-imide coating has been shown to have good resistance to water but can be unstable in UV radiation (2,900-4,000Kcals) (Alvino, 1971). This is because it is intended to be used inside motors and has not been designed to resist UV degradation. However, this is a significant 
shortcoming with respect to the way it is used at RBGE because it is constantly exposed to high UV levels. Close examination of the wire on the labels of specimens in the Chinese Hillside area at RBGE revealed that the protective coating was flaking off and oxidisation was evident on the exposed wire core (see Fig. 2).

Copper does not leach readily in water and needs to be oxidised $(\mathrm{CuO})$ before it becomes soluble. This can occur in drinking water when chlorine and water with a low $\mathrm{pH}$ combine to oxidise the copper piping in homes (Hong \& Macauley, 1997). Copper can also oxidise in sulphuric and acidic rainwater (also known as 'acid rain'), which reacts to form copper sulphate $\left(\mathrm{CuSO}_{4}\right)$. Sulphur deposition in the UK due to acid rain has reduced considerably since records began in 1987. The highest concentrations occur in the Midlands and London with small concentrations over Glasgow and Edinburgh (Fowler et al., 2004).

On 5 March 2011 a simple test for copper leach was performed using an aquarium test kit. This was to test the theory that copper leaches from the wire and acts as a poison when it runs over the bark of the plant. A new piece of wire $28 \mathrm{~cm}$ long was soaked in $10 \mathrm{ml}$ of rainwater and was agitated at eight-hour intervals for one minute. A $2 \mathrm{ml}$ sample of the water was then tested for copper content. The test was repeated with seven pieces of wire cut into $4 \mathrm{~cm}$ lengths (to expose cut and unenamelled ends) and again with a

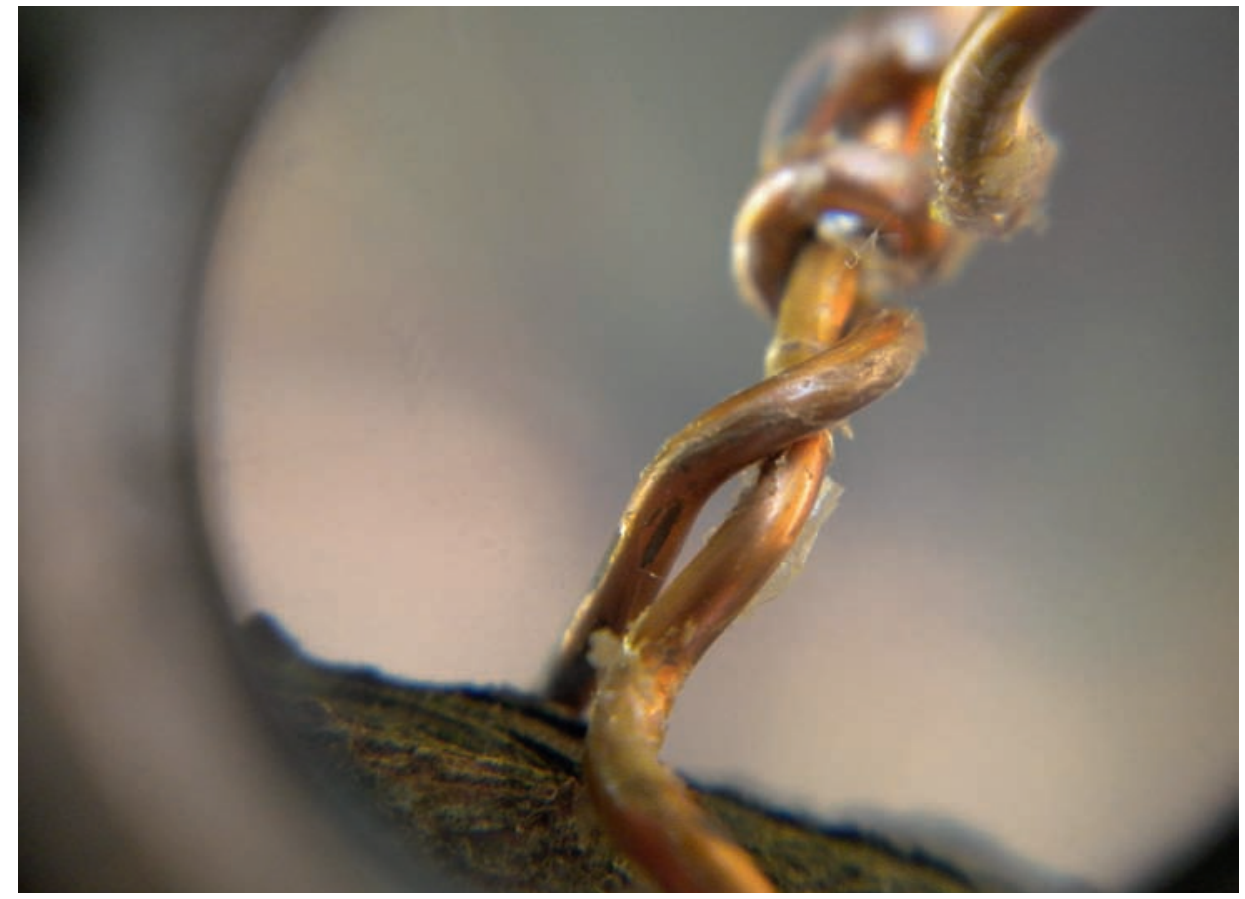

Fig. 2 Copper wire showing the protective layer breaking down and flaking off. Photo: Paul Bradley. 
$28 \mathrm{~cm}$ length of weathered wire of indeterminate age. One sample of rainwater with no wire added was tested as a control sample.

The control and fresh wire samples tested negative for copper after 24 hours. The water with the cut wire sample tested positive for copper at $0.1 \mathrm{ppm}$. The older, weathered wire resulted in a solution 20 times more concentrated with a copper content of $2 \mathrm{ppm}$. This proves that when the protective enamel coating is not present copper leaches from the wire as acid rain induced copper sulphate. This will have implications for plant health.

\section{SURVEY OF THE LIVING COLLECTION}

The Living Collection at RBGE is spread over four Gardens in Scotland: the Edinburgh Garden and three Regional Gardens, Logan Botanic Garden in Dumfries and Galloway, Dawyck Botanic Garden in the Scottish Borders and Benmore Botanic Garden in Argyllshire. Paul Bradley spent one full day surveying plants with labels on the lower branches in each garden. The visits were made in spring so that the presence of new leaf growth would facilitate the identification of dead branches. Each accessible branch-labelled tree or shrub was checked for branch death and the position of the label assessed. Where both were found, a photograph was taken which included the accession number and species, and an assessment of the general vigour of the whole plant made. A rating of the health of the plant on a scale of $1-5$ was used with 1 being excellent and 5 being very poor. Any signs of damage near the label attachment point were separately photographed and noted. This data was entered into one spreadsheet with additional comments where relevant. The plant record database $B G-B A S E^{\mathrm{TM}}$ (Walter \& O'Neal, 1985-2010) was used to compare the numbers of the most affected genera with the total number of each growing at RBGE.

Over the four Gardens, 120 specimens were found to have a label on a dead branch: 44 per cent were in the family Ericaceae, 32 per cent in Rosaceae, 5 per cent in Berberidaceae and 3 per cent in Sapindaceae, with 18 per cent in other families. Forty-one per cent of plants with dead branches were in the genus Rhododendron, which represents 0.5 per cent of the Living Collection. Ten per cent were in the genus Sorbus, which represents 1.1 per cent of the Living Collection. Seven per cent were in the genus Spirea, which represents 0.9 per cent of the Living Collection. The rest were in other genera. The occurrence of dead branches found were equally spread over the Gardens, with the exception of Logan, where very few were found. The condition of the plants recorded with dead branches was mostly classified as 'good' or 'average', with 13 per cent deemed to be in 'poor' condition (see Fig. 3). Therefore most plants with dead branches were in otherwise good condition. $B G-B A S E^{\mathrm{TM}}$ records were used to determine the age of the plants with dead branches. Almost all of them were mature specimens; the youngest was 6 years old and the majority were over 30 years old. The oldest was 92 years old.

On a number of plants the bark was damaged where the wire was attached. Some Acer species had discoloured bark around this point. At Dawyck and Benmore, where 


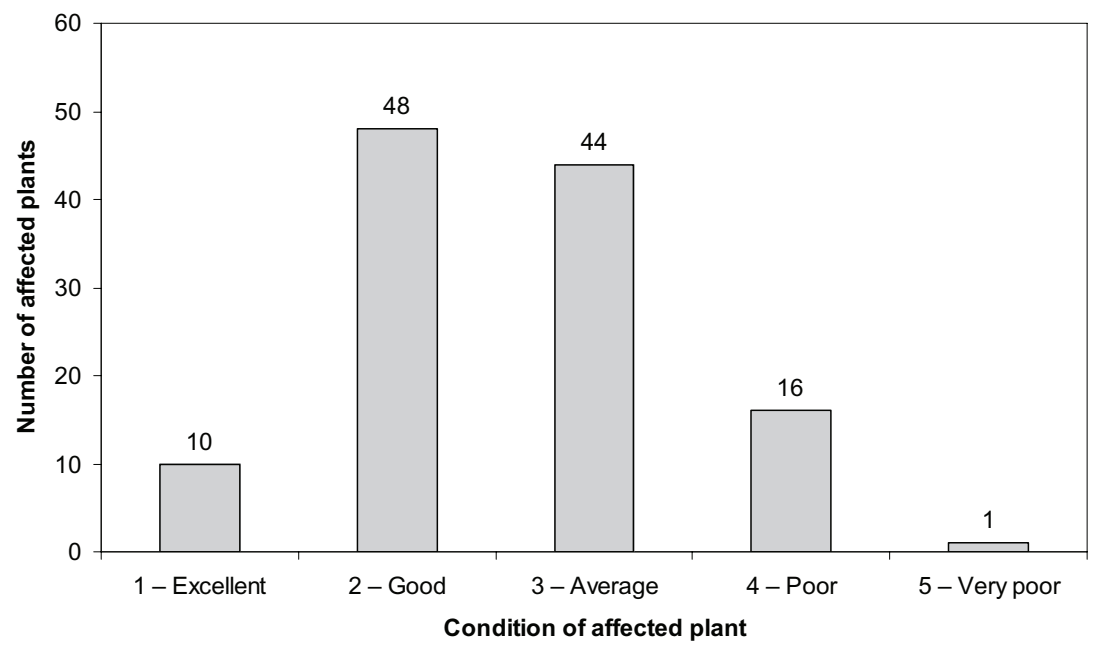

Fig. 3 Graph showing the number of plants by condition with dead branches.

lichens and mosses are more common on the trees and shrubs, it was normal to find the area around the attachment area completely devoid of these (see Fig. 1).

There were two plants at Benmore where the tally tag was attached with plastic ties on different branches from those with the copper-wired display label. The branch with the copper wire was dead but the one with the tally tag was healthy.

No examples of damage to plants by labels were found in the Indoor Department at Edinburgh; the plants in this department are under glass.

Where the copper wire was discoloured through ageing, bleaching or lightening of the black display label was noticeable around the attachment points and below on the tag face (see Fig. 4).

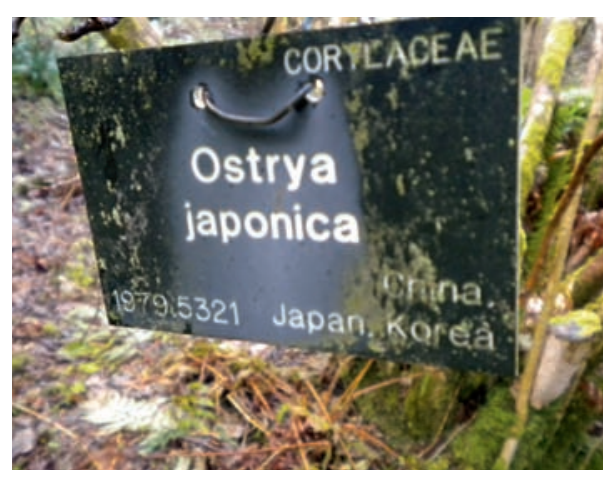

Fig. 4 Label showing the effects of copper leaching and run-off from weathered wire at Dawyck Botanic Garden. Photo: Paul Bradley.

\section{SURVEY OF LABEL USE IN BOTANIC GARDENS}

In order to see whether the correlation between the use of copper wire for hanging labels and branch death recorded at RBGE had been noticed in other botanic gardens the authors emailed an introduction and web link to a short, semi-structured questionnaire to selected botanic gardens around the world, using the Botanic Gardens Conservation 
International (BGCI) member list as a basis. Responses were automatically entered into a secure online spreadsheet for later analysis. The authors successfully delivered 354 questionnaires, and the response rate was 23 per cent. While this was low, probably due to the introduction and web questionnaire being available only in English, it was nevertheless an acceptable rate and yielded useful information.

The structured elements of the questionnaire gave the following results: 82 per cent of respondents hang labels on the branches of their trees and shrubs. Of the 18 per cent who do not do this, 35 per cent cited risk of damage as the reason, while 7 per cent do not use labels for historic reasons, 7 per cent for financial reasons and 7 per cent for aesthetic reasons; the remainder use engraved labels on a post placed next to the plant.

Of those who do hang labels on branches, 5 per cent use galvanised wire, 12 per cent use copper wire, 6 per cent use plastic ties, 3 per cent use string, 45 per cent use plastic-coated wire and 6 per cent use aluminium wire. The remainder use a combination of other methods.

Of those respondents who hang labels on branches, 75 per cent were not aware of any label-related branch damage. Of the 25 per cent who were aware of damage, 88 per cent had noticed it on fewer than 50 plants in their collection. Of those who were not aware of any label-specific damage, 54 per cent use plastic-coated metal wire. However, of those who did report damage, 53 per cent also use plastic-coated metal wire.

The nature of the damage caused was reported as follows: 50 per cent had noticed branch death, 6 per cent had noticed poor leaf production, 38 per cent had noticed bark discolouration and 31 per cent had noticed stripped bark. However, there was no clear pattern to the genera affected. Most gardens reported that the main problem was accidental girdling of branches through neglect, which could happen to any species. Three gardens remarked that branches appeared to die without any sign of constriction.

At the end of the survey there was a box for additional comments. The responses included in this were useful and many respondents took the opportunity to explain their labelling system and experiences thoroughly. A few digressed into the equally interesting subject of trunk tagging, which would make for a fascinating study on its own.

Quarry Hill Botanical Garden in California, USA reported that "loosely hanging labels on insulated wire seemed to affect branch health in some cases" and suggested that this could be due to "movement, pressure or a magnetic/electrical field inhibiting the vascular system" (Higson, pers. comm.). Similarly, Leigh Morris at RBGE reported that while working in the commercial nursery trade he had observed branch death at a large nursery in Yorkshire on over 100 pot grown hybrid tea and floribunda roses with loose Tyvek ${ }^{\circledR}$ (plastic) labels attached (Morris, pers. comm.). Kyle Port of the Arnold Arboretum in the USA commented that: "Anecdotal evidence indicates that the branch that the label is attached to 'always dies'. I've noticed shrubby members of the Rosaceae suffer this fate. Our greater use of stakes with labels attached minimizes the phenomena. On the arboreal side, Sorbus and Magnolia stand out in my mind."

A number of respondents expressed an interest in the study and requested that they be notified of the findings. 


\section{ANALYSIS OF DEAD BRANCH MATERIAL}

Dry matter analysis is recommended by Kuhns \& Sydnor (1976) as the most reliable method of assessing copper-related plant damage. The test is expensive and ideally requires $100 \mathrm{~g}$ of plant material for analysis, which equates to a large branch. Consequently, only one branch was chosen which came from a good example of a healthy plant with one dead branch on which a label with copper wire had been hung. Although the results were interesting, they were not conclusive. A test of ten dead branches alongside ten live branches from each corresponding plant would have yielded more conclusive results but would have a relatively high cost at $£ 600$. A test on this scale would be valuable on controlled long-term plant trials.

On 13 April 2011, one dead branch was removed from Rhododendron crinigerum var. crinigerum (accession no. 19698494A) at RBGE. This was shredded and found to weigh $80 \mathrm{~g}$. It was sent for Dry Matter Organic Waste and Organic Waste Mineral testing at the Scottish Agricultural College (SAC) Analytical Services Department. The test was to assess levels of: phosphate, potash, calcium, magnesium, sodium, zinc, copper, manganese, iron and sulphur.

Iron and manganese levels can be linked to copper poisoning (Kuhns \& Sydnor, 1976). The results of the dry matter analysis at SAC found copper levels at $6.23 \mathrm{mg} / \mathrm{kg}$ in the stem tissue and manganese levels of $634 \mathrm{mg} / \mathrm{kg}$.

\section{DISCUSSION}

It must be recognised that there is no way to know how many dead labelled branches have been pruned or have fallen off over the years that the labels have been in use at RBGE; the figures in the study are therefore not comprehensive.

The total number of plants found at RBGE with dead labelled branches was quite small in relation to the number of trees and shrubs in the Living Collection. However, one point of view is that any unnecessary plant damage is unacceptable.

The age of the plants appears to be important in the occurrence of lower branch death. Older plants have old lower branches and tend to be taller and have larger canopies that shade the low branches. Thus, it may be that lower branch death is a natural phenomenon.

The occurrence of branch death was higher in the families of Ericaceae and Rosaceae; this was supported by comments from staff at the Arnold Arboretum (Port, pers. comm.). These are herbaceous and woody plant families so there is no way to assess the proportion of branch-labelled specimens affected without a highly detailed survey of the Living Collection. It should be noted that RBGE has a large proportion of both these families in the Living Collection, which may account for the high number of branch deaths. A good example of this is the genus Rhododendron, which had the highest number of affected plants. There are many species and accessions of these at RBGE; the percentage of specimens with dead and labelled branches was very small at 
0.5 per cent even though the numbers appeared high. The woody members of Ericaceae and Rosaceae tend to have thinner bark than many other families and bark damage was visible in a number of instances. Two girdling studies (Hamada et al., 2008; FernandezEscobar et al., 1987) show that point-specific damage to the outer layers of woody plants can cause physiological damage, particularly to the transfer of nutrients and sugars and to the xylem.

Girdling was stated as the main cause of labelled branch loss by the majority of damage-aware respondents to the questionnaire.

The questionnaire showed that the most popular attachment material is plasticcoated metal wire. There was no correlation between the attachment material used and the damage; this may be because the main damage reported was strangulation, which can happen with any material. Copper wire was of particular interest in this study because it is used at RBGE. However, it was only used by 10 per cent of respondents and of those who did use it, most reported no damage.

The copper wire currently used at RBGE is Magnetemp ${ }^{\circledR}$ CA 200 and the protective coating does break down in UV light, as observed in the Living Collection survey; this corresponds to the findings of a previous study (Alvino, 1971). Acid rain is still evident over Benmore and Edinburgh (Fowler et al., 2004). Once the coating has broken down, acid rain can cause the copper to leach out of the wire.

Copper levels leached from older, weathered wire were present at a level capable of causing chronic symptoms in species of Rhododendron (Ericaceae) and Cotoneaster (Rosaceae) according to the toxicity study of Kuhns \& Sydnor (1976). However, in the case of the branches analysed copper did not seem to be responsible for branch death. More samples of dead branches would need to be tested to obtain conclusive results.

Plantings of Cotoneaster and Spiraea, which are thin-barked species, in exposed positions at Dawyck did suggest a link between exposure to the elements and labelled branch death. The lack of examples found on plants growing under glass corroborates this link.

Logan Botanic Garden is the smallest of the RBGE sites and a lower number of seemingly susceptible Rhododendron sp. are planted in this garden. In addition, most of these are in the protection of the walled area and immediate surroundings so if exposure to wind and rain is a factor in branch death these conditions would explain the lower number of examples of dead branches. Logan is also less affected by acid rain than the other three RBGE sites (Fowler et al., 2004).

The number of staff per hectare has an effect on the dead-wooding regime and so one possible explanation for Dawyck and Benmore having the largest number of affected plants is because they have fewer staff per hectare than the other two sites.

\section{CONCLUSIONS AND RECOMMENDATIONS}

The results of this preliminary investigation indicate that the following factors can result in the death of a branch with a label tied on with copper wire: 
- thin bark

- age

- weathering of the wire

The ingress of disease or toxic material also seems to be a plausible reason for death but further testing is required to prove this.

It is recommended as a result of this study that the way to test the effects of different branch label attachments is with long-term label trials. Microscopic analysis of branch material at cell level is possible using the technique of paraffin sectioning. This would be a useful method to determine physiological damage occurring at unscarred label attachment points. These tests are detailed and time-consuming, but the required facilities exist at RBGE and this type of analysis could be carried out in the future.

Until technological advancements in GPS mapping and handheld DNA analysis devices are made, which may negate the need for plant labels altogether, it is recommended that the following amendments be made to the RBGE cultivation and labelling practices:

- When deadwooding thin-barked species, staff should not remove dead labelled branches as the next branch used to hang the label may suffer the same fate.

- Labels should be attached to stakes next to thin-barked shrubs and young trees wherever possible rather than attached to the branch. Existing accessions should be altered accordingly.

- Weathered and discoloured wire should be replaced.

- Label wire should be loosened to prevent constriction of branches as part of the stocktaking process.

- Labels should not be attached to the leaders of any trees.

Although branch death due to phytotoxicity caused by leached copper seems plausible it remains unproven. There were three conclusive findings relating to wire material used at RBGE:

- The protective coating breaks down over time.

- Older oxidised copper wire discolours the display labels.

- Copper wire of any age must not be used with the tally tags.

As a result of these findings it is suggested that plastic-coated galvanised metal wire should be used. It may also be of interest to staff managing resources that it is 58 per cent cheaper than copper wire.

The level of interest expressed by international gardens in the process of carrying out the questionnaire, combined with a lack of previous studies, indicates that this topic may merit further investigation at RBGE. The results could be of global interest and provide valuable input to discussions surrounding botanic garden labelling. 


\section{REFERENCES}

ALVINO, W.M. (1971). Ultraviolet stability of polyimides and polyamide-imides. Journal of Applied Polymer Science, 15, 2,123-2,140.

FERNANDEZ-ESCOBAR, R., MARTIN, R., LOPEZ-RIVARES, P. \& PAZ SUAREZ, M. (1987). Girdling as a means of increasing fruit size and earliness in peach and nectarine cultivars. J. Hort. Sci., 62, 463-468.

FOWLER, D., SMITH, R.I. \& SUTTON, M.A. (eds) (2004). Acid deposition processes. Final report to the Department for Environment, Food and Rural Affairs. EPG 1/3/166.

GOREN, R., HUBERMAN, M. \& GOLDSCHMIDT, E.E. (2010). Girdling: physiological and horticultural aspects. Horticultural Reviews, 30, Chichester: John Wiley and Sons.

HAMADA, K., OGATA, T., FUJIWARA, S. \& HASEGAWA, K. (2009). Healing process of the wounds of the branches of the Japanese persimmon that were caused by girdling, scoring, and strangulation. Scientia Horticulturae, 120, 276-281.

HONG, A. \& MACAULEY, Y. (1997). Corrosion and leaching of copper tubing exposed to chlorinated drinking water. Water, Air, \& Soil Pollution 108(3-4), 457-471.

HORTICULTURAL DIVISION (2004). Horticulture Division Method Statement 3.5.4 \& 3.5.5. Royal Botanic Garden Edinburgh: Unpublished.

KUHNS, J. \& SYDNOR, T. (1976). Copper toxicity in woody ornamentals. Journal of Arboriculture 90(75).

MAURER, R. (1999). Labelling our Collections - Results of a survey. BGCI Report, 3(3). Available at: www.bgci.org/worldwide/article/124 (accessed May 2011).

WALTER, K.S. \& O'NEAL, M.J. (1985-2010). BG-BASE [Collection Mangement Software]. BG-BASE Inc. \& BG-BASE (UK) Ltd. Available at: www.bg-base.com (accessed September 2011). 
